Association for Information Systems AIS Electronic Library (AISeL)

Wirtschaftsinformatik Proceedings 2005

Wirtschaftsinformatik

February 2005

\title{
Learning from Experience: Towards a Formal Model for Contextualization of Experiences for Quality Development
}

\author{
Markus Bick \\ University of Duisburg-Essen \\ Ulf-D. Ehlers \\ University of Duisburg-Essen \\ Jan M. Pawlowski \\ University of Duisburg-Essen \\ Heimo H. Adelsberger \\ University of Duisburg-Essen
}

Follow this and additional works at: http://aisel.aisnet.org/wi2005

\section{Recommended Citation}

Bick, Markus; Ehlers, Ulf-D.; Pawlowski, Jan M.; and Adelsberger, Heimo H., "Learning from Experience: Towards a Formal Model for Contextualization of Experiences for Quality Development" (2005). Wirtschaftsinformatik Proceedings 2005. 40.

http://aisel.aisnet.org/wi2005/40

This material is brought to you by the Wirtschaftsinformatik at AIS Electronic Library (AISeL). It has been accepted for inclusion in Wirtschaftsinformatik Proceedings 2005 by an authorized administrator of AIS Electronic Library (AISeL). For more information, please contact elibrary@aisnet.org. 
In: Ferstl, Otto K, u.a. (Hg) 2005. Wirtschaftsinformatik 2005: eEconomy, eGovernment, eSociety; 7. Internationale Tagung Wirtschaftsinformatik 2005. Heidelberg: Physica-Verlag

ISBN: 3-7908-1574-8

(C) Physica-Verlag Heidelberg 2005 


\title{
Learning from Experience: Towards a Formal Model for Contextualization of Experiences for Quality Development
}

\author{
Markus Bick, Ulf-D. Ehlers, Jan M. Pawlowski, \\ Heimo H. Adelsberger \\ University of Duisburg-Essen
}

\begin{abstract}
Quality development in e-learning becomes more and more important. A variety of quality approaches have been developed to improve educational processes in this field. The implementation of these approaches, however, often lacks success. One important reason is that experiences and recommendations are not systematically utilized for the implementation processes. The following article suggests a formal approach to collect and share experiences and recommendations to help users of quality approaches enhance their success by reusing experiences of others. Based on knowledge management principles, the contextualization of experiences will help to transfer them from one specific situation to a different context. The suggested approach is a result of the European Quality Observatory, an analysis and information platform for quality approaches in European e-learning.
\end{abstract}

Keywords: Experience Sharing, Quality Management, Knowledge Management, Quality Decision Process

\section{Introduction}

The number of quality approaches that have been developed for the different educational fields, along with the large number of methods (such as criteria lists, guidelines, management approaches), has grown to an unmanageable amount (a comprehensive overview can be found in [EhPG2003]). However, it is not just the number which makes it difficult to select a suitable approach, but the often divergent intentions and recommendations of the approaches as well. On the European level, this problem becomes even more severe because of different cultural contexts, languages, and educational systems come in, resulting in a vast multitude of diverse regional and differentiated sectoral approaches.

Therefore, the decision which quality approach is suitable for an educational organization is a highly complex task - which envisioned as a decision process - can 
be called the Quality Decision Process. This paper describes how experiences made by users of quality approaches can be described and structured in a standardized way and thus become searchable and accessible. We show how the quality decision process as well as the process to use and implement quality approaches can be supported by using knowledge management principles: the formalization and reuse of experiences to improve quality development.

The proposed method for this ambitious aim is to construct a formal model which allows to analyze experiences, and to specify recommendations against the background of their contexts. The difficulties and the boundaries of such an approach are quite clear from beginning: can there be something like a generalization of experiences - defined as perceptions in a specific context - at all? The methodology we propose to enhance quality development is based on formal description models to enhance decision processes and to make recommendations according to certain characteristics. We provide solutions to analyze and compare quality approaches and thus improve the fit between organizational and individual requirements and the selection of quality approaches resp. strategies.

With this work we reach beyond a methodology for choosing and recommending quality approaches - developments which are already implemented in the "European Quality Observatory (EQO)", a European portal for e-learning quality. The mechanisms already implemented there provide support for quality development in e-learning through profile based recommendation mechanisms [MaSa2004]. With this paper we are also looking into combinations of knowledge management approaches and quality development because we believe that apart from finding the appropriate solution, the implementation process is of critical importance for the success of every quality project in organizational contexts.

\section{Knowledge Management for Quality Development in E-Learning}

\subsection{Quality Development in E-Learning - a Learning Cycle Building on Experiences}

Quality in e-learning decides over success or failure for this form of learning. This is quite clear today - on a national level as well on an international level. However, because of the nature of the concept "quality", what it means is highly depending on perspectives and contexts, and how it is achieved is a field of great debates. Today, it is apparent that quality on the one hand is a very important factor on all educational levels in European education, but on the other hand is a moving target without clear cut definitions, understandings, and ways to achieve it. We 
have described reasons and dimensions for that in [Ehle ${ }^{+} 03 \mathrm{~b}$, Ehle2004] which state that quality in e-learning in Europe is a field of great diversity: Many different approaches on different levels, for different educational sectors, contexts, and target groups compete with each other in the area of quality management, assurance, and assessment. Not only different techniques and methods to enhance quality in e-learning are used here, but also different levels of educational quality in the various approaches, and different concepts of quality itself can be recognized (e.g., pedagogical quality, technological quality, economical quality, etc.). Approaching this field on a European level (i.e., beyond the borders of national discourses) makes it even more complex.

The problem with finding a suitable approach for a specific educational purpose, e.g., improving the learner support in an e-learning course for secretaries, is no longer that there are too few approaches to choose from, but rather that it is difficult to structure the divers field of approaches properly, and to map a set of requirements against the approaches available. The European Quality Observatory (http://www.eqo.info) addresses this problem by providing a formal model for describing quality approaches and thus making them comparable and searchable in a database.

However, it becomes more and more evident that quality development is not only a matter of finding a suitable approach but also strongly depends on an appropriate implementation process, and moreover on aspects which vary from context to context: Staff trainings, motivational conditions, organizational restructuring processes, costs, and alike. Depending on how much quality development focuses on changing, resp. redefining individual work patterns, believes, and values, it can be envisioned as a learning process itself. For organizations, we consider three possible groups of strategies for quality development. The first group of strategies we call official external strategy, the second we call official internal strategy and the third groups of strategies we call implicit strategies:

- Official External Strategy: Quality strategies or instruments coming from externally adopted approaches (e.g., ISO, EFQM, BAOL Quality Mark)

- Official Internal Strategy: Quality strategies that are developed within an organisation but still apply to the organisation as a whole or parts of it specifically

- Implicit strategies: Quality development which is not part of an official strategy but rather left to individuals' professional activities.

For the two official strategies, quality development is part of the official organizational policy. Quality in these cases can be envisioned as a learning cycle rather than an isolated single occasion. It usually aims at changing organizational processes and addresses actors to change their "traditional" patterns of behavior. Quality development in those cases deals with applying new rules and proceedings but it will only be successful if it aims at stimulating awareness for quality improve- 
ment on the side of the organizations' members. Therefore, quality development in an organization always builds on changing behavior, competencies, and believes of its members. At this point it becomes quite obvious that mechanisms which apply to learning and knowledge management processes also apply to organizational change processes in form of quality development. To enable organizational actors to learn from others' experiences, e.g., of previous implementation processes, therefore bears important potential to raise success of quality improvement processes in education. It becomes clear that one important factor of quality development - apart from a methodology and a value model - is knowledge management which aims at stimulating learning processes in actors' competence development processes.

Our research in this field addresses aspects of success and failure in implementation of quality improvement strategies. It means to explore, classify, and assess the impact which quality approaches have on the various processes of the educational environment, and to gain knowledge about implementation processes. Therefore apart from describing quality approaches - we are concerned with finding formal, generic description categories for experiences and recommendations which users of quality approaches have. In order to make such experiences reusable, they have to be analyzed according to the related context. The identification of such attributes enables transfer of experiences into different contexts.

This leads to the conclusion, that research on the experiences which organizations' individual actors make, during and after the implementation process of quality approaches, is necessary. More knowledge is needed about the context factors which determine success or failure of quality approaches, and about how quality approaches can/should be adapted according to those contexts. In addition research about the possibility of transferring relevant experiences from one to another context is necessary. The aim is to derive generalizable knowledge from the analysis of subjective perceived effects of the implementation and use of quality approaches in specific contexts. Learning from experiences thus means to find recommendations from implementation and usage experiences.

\subsection{Learning to Share Experiences from Knowledge Management}

Reuse and transfer of knowledge is one important element for improvement - as we have seen both in the field of knowledge management as well as in the field of quality development. As described above, the reuse of experiences can become an important factor for quality development in education as well. However, especially in the field of education, reusing and assessing experiences for quality development purposes is fairly new ground. In the following we show how knowledge management concepts can be applied to the above mentioned learning and decision processes. This work is based on previous work as described in 
[ABLP2004]. During the past decade, knowledge management has emerged as one of the most important and widespread management issues. Knowledge management finds its origins in a desire to learn from mistakes and to hinder the "reinvention of the wheel" in organizations [ReRa2001]. In the past decade, the importance of knowledge as a key resource has become well established (cf., e.g., [Druc94; Maie2002]).

We use a definition of knowledge management by MAIER which is on the one hand general enough to support all kinds of different knowledge areas and on the other hand regards management in a functional sense:

"Knowledge management is defined as the management function responsible for the regular selection, implementation, and evaluation of goal-oriented knowledge strategies that aim at improving an organizations' way of handling knowledge internal and external to the organization in order to improve organizational performance. The implementation of knowledge strategies comprises all personoriented, organizational, and technological instruments suitable to dynamically optimize the organization-wide level of competencies, education, and ability to learn of the members of the organization as well as to develop collective intelligence." [Maie2002, 55]

Although MAIERS' definition has a slightly technocratic notion and it could be debated wheather it is possible at all to stimulate individual competency development through external strategies, we still want to use an important distinction. According to this definition, two approaches to knowledge management exist: $h u$ man-oriented (personalization strategy) and technology-oriented (codification strategy) [HaNT1999; Lehn2000]. This terminology shows the two sides of knowledge management which can be differentiated between (see also Table 1):

- Human-oriented/personalization strategy: Knowledge is closely tied to the person who constructed it. Knowledge is mainly shared through direct personto-person contacts. Information and communitcation technology (ICT) just supports people to communicate knowledge, not to store it. One example in our context is experience sharing within a community or within an organizational context in which activity patterns change and people share their experiences because of quality development processes.

- Technology-oriented/codification strategy: This strategy addresses the computer technology resp. ICT: Information is (carefully) codified and stored in 'databases' where it can be accessed and used easily [HaNT1999]. The formal model of experiences is an example which could be used in the frame of such a strategy to supply people with a standardized set of infomration.

Besides this, more recent knowledge management approaches suggest to follow a holistic approach of knowledge management, bridging the gap between humanoriented and technology-oriented knowledge management [Albr1993; Lehn2000]. Hansen et al. [HaNT1999] identified certain strategy-mixes within their survey: A 
company pursues one strategy predominantly and uses the second strategy to support the first.

\begin{tabular}{|c|c|c|}
\hline & human-oriented & technology-oriented \\
\hline $\begin{array}{l}\text { knowledge man- } \\
\text { agement strategy }\end{array}$ & Personalization & Codification \\
\hline $\begin{array}{l}\text { comprehension of } \\
\text { knowledge }\end{array}$ & $\begin{array}{l}\text { knowledge is contained in } \\
\text { peoples head }\end{array}$ & $\begin{array}{l}\text { Knowledge is rather } \\
\text { understood as stored, } \\
\text { documented informa- } \\
\text { tion, detached from em- } \\
\text { ployees }\end{array}$ \\
\hline actors/roles & $\begin{array}{l}\text { knowledge worker, net- } \\
\text { works, and communities } \\
\text { of interest }\end{array}$ & $\begin{array}{l}\text { authors, experts, infor- } \\
\text { mation broker }\end{array}$ \\
\hline $\begin{array}{l}\text { knowledge man- } \\
\text { agement systems } \\
\text { (KMS) } \\
\end{array}$ & $\begin{array}{l}\text { interactive knowledge } \\
\text { management systems }\end{array}$ & $\begin{array}{l}\text { integrative knowledge } \\
\text { management systems }\end{array}$ \\
\hline $\begin{array}{l}\text { important knowl- } \\
\text { edge management } \\
\text { system functions }\end{array}$ & $\begin{array}{l}\text { communication and coop- } \\
\text { eration, allocation of ex- } \\
\text { perts, community-support, } \\
\text { human captial manage- } \\
\text { ment }\end{array}$ & $\begin{array}{l}\text { publication, structuring } \\
\text { and integration, search, } \\
\text { presentation and visu- } \\
\text { alization of information } \\
\text { elements }\end{array}$ \\
\hline EQO component & $\begin{array}{l}\text { Community, expert net- } \\
\text { work, experience sharing }\end{array}$ & $\begin{array}{l}\text { Formal experiences, } \\
\text { analysis model }\end{array}$ \\
\hline
\end{tabular}

Table 1: Classification of Knowledge Management Approaches and Systems based on [MaHä2001]

ICT is the enabler for knowledge management activities, especially technologyoriented knowledge management. Correspondingly, a great variety of so called knowledge management systems (KMS) arose (cf., e.g., [EpSe2000; Lehn2000; Klos2001; Maie2002]). With regard to the above mentioned knowledge management approaches (see Table 1), we can derive a distinction between integrative knowledge management systems, focussing on method-, product-, and process knowledge, and interactive knowledge management systems, focussing personoriented knowledge [MaHä2001; Maie2002b]:

- Integrative knowledge management systems: support the codification of information search and retrieval as well as the administration of information repositories and the organization of knowledge structures. The European Quality Observatory provides methods for codification, search, and retrieval.

- Interactive knowledge management systems: support location of experts, their communication and collaboration, provides shared homespaces for communities, and modern e-learning instruments. The European Quality Observatory 
provides a community in this context, including possibilties to improve communication and cooperation. People can therefore get in contact about their quality development strategies and challenges, offer their knowledge, and reflect on experiences.

Furthermore, MAIER [Maie01] identifies functions bridging the gap between knowledge integration and knowledge interaction, especially for supporting knowledge intensive (business) processes. In our context, the specific (business) process is the choice and implementation of quality approaches for educational organizations (see also next section). In this respect, we link business processes to knowledge management processes in our concept. In our view, this link is crucial to every qality development process - including the subprocesses of choosing the right strategy and implementing/introducing a quality strategy into an organization. The term process is used with respect to knowledge management in three connotations [Remu02]:

- knowledge-intensive operative (business) process denotes a (business) process that relies substantially on knowledge and relates to organizations core competencies on the operative level: e.g., choice and implementation of a quality approach for an organization.

- knowledge process refers to a dedicated service- or support process which supports the flow of knowledge within and between knowledge-intensive operative (business) processes: e.g., search, analysis, etc.

- knowledge management process

is a 'meta'-process that is responsible for the extensive implementation of the knowledge management initiative: e.g., organizational instruments, ICT instruments, controlling, etc. 
Figure 1 depicts the link between knowledge-intensive (operative) business processes and knowledge processes.

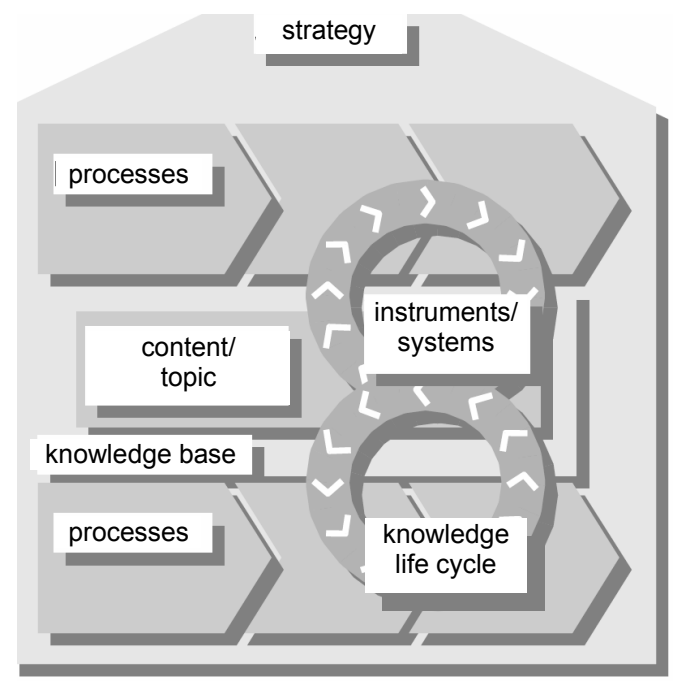

Figure 1: Process orientation according to [Remu02]

As we have shown in this chapter, the complex Quality Decision Process as a knowledge intensive (business) process can be supported by different knowledge management strategies, such as codification and personalization. Moreover the introduction or implementation process relates to such processes as well.

\section{European Quality Observatory - Providing a Decision Cycle for Quality Strategies}

The European Quality Observatory (EQO) is an information, knowledge, and support source for educational institutions and other organizations, as well as for users. In the following, EQOs' contribution to the previously presented Quality Decision Process is shown and the decision process - envisioned as a cycle - itself will be described.

The Quality Decision Process consists of four phases (see Figure 2). In the first phase, quality apporaches are collected. These approaches are analyzed using the so called EQO Model - the EQO model is a conceptual model to describe, compare, and analyze quality approaches (for EQO model: [EHPT2004] or 
http://www.eqo.info). After this analysis, usually several quality approaches are chosen as alternative solutions for an organization - this decision process is based on preference profiles which we provide for assesment. Finally, a decision for one apporach is made - the approach then needs to be adapted and in parts be redefined, leading to an organization-specific approach. Figure 2 shows the decision process and the results of the harmonization.

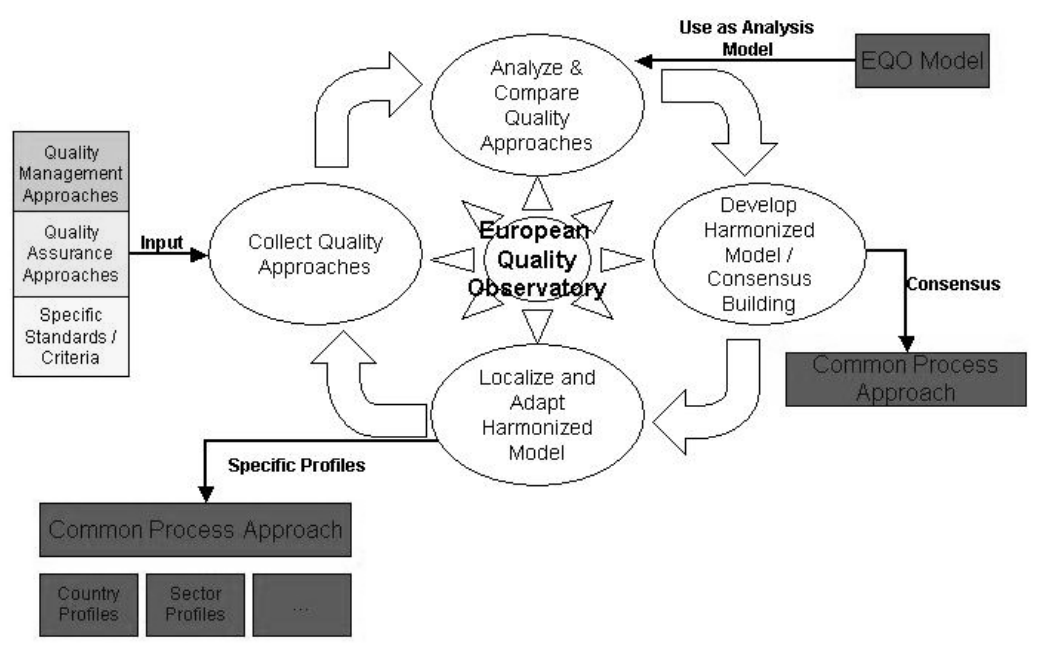

Figure 2: Quality Decision Process [EhPa2004]

This decision cycle is supported through the different information and community services EQO offers:

- Structuring and comparing quality approaches for the field of e-learning: The variety of quality initiatives (e.g., ISO 900x:2000, EFQM) and quality approaches (e.g., different abstraction levels, national/regional/local approaches, domain specific approaches, process-orientation / product-orientation / competency-orientation) leads to a increasing confusion in the community. There is no accepted quality-mark for organizations or products on a European or global level. Therefore, the approaches are compared, classified, and transparently structured in the EQO repository - which is internet accessible - in order to provide a survey of actual approaches. The repository provides information for decision makers in organizations and users in the field of E-learning. Different levels of abstraction are be covered: Quality management, quality assurance, and quality assessment. By providing structured, context-related information, the analysis phase of the decision process is supported.

- Building a community of practice in order to reach a common understanding of and increase expertise on the concept of "E-Learning Quality": The first 
parts are part of the codification strategy. However, EQO integrates these approaches into a personalization strategy by providing a community and methods to improve communication and cooperation.

Currently, various initiatives, projects, and experts deal with the issue of quality for E-learning separately. There is no central platform for the exchange of information and expertise. By building an interactive community of practice, users and experts from different contexts can start the exchange of information, experiences, and expertise.

The next step towards a knowledge management approach for quality development in e-learning would be to provide information retrieval, recommendation, and communication possibilities which are individually designed for specific organisational contexts in the field of e-learning.

\section{The Difficulty of Finding a Formal Model for the Evaluation of Experiences}

In this chapter we will present a solution for the above discussed problem of standardizing the description of experiences. A formal model for such a description has to meet four requirements which will be discussed first. In a second step the formal model itself will be presented, consiting of three sections: general information, recommendations, and assessment.

\subsection{Conditions and Constraints in Classifying Experiences}

Learning from experiences is a difficult task because experiences are usually highly context specific. Therefore it is difficult to map existing experiences to other specific contexts. The method we propose to use in order to make experiences reusable is to develop a formal model which specifies standardized categories for the description of experiences. Information on experiences could then be mapped to certain contexts, could be searched by certain keywords, and can altogether be examined in a systematic way to find generalized structures. To map those experiences to specific contexts, we need to structure and formalize the description of this information. 
We know that experiences on quality approach implementation processes cannot easily be generalized because of their specific, related context. Each of those experiences on the other hand could contain valuable information for (other) organizations which may find themselves in a similar situation and face the same or similar problems.

The challenge in finding a description model therefore is twofold: a) to find appropriate description categories that are restrictive enough to make experiences comparable and b) to find a suitable way of being open enough in description, so that individual characteristics can still be integrated into such a description. Such a model therefore has to be open at certain parts and clearly structured into predefined categories in other parts, to meet theses challenges. This goal can only be achieved against the background of four conditions/ restrictions:

1. Restrictive in description but holistic in coverage: The model which we are looking for, has to be capable of describing experiences concerning the whole educational process; in this sense it has to be holistic. It can not be reduced to certain processes only, the learning phase or the evaluation phase in the end of a course, for example. It must allow a description of experiences for all processes which a quality approach can possibly affect. On the other hand it has to be able to structure actors' experiences in a way which allows others to learn from them. They must be transferable, applicable, structured, and searchable.

The solution for this, on first sight contradictory requirement, is the integration of a well structured process model with a model for describing experiences. It allows to describe experiences or recommendations for the use of quality approaches for specifically those educational processes which are affected. Collections of data about what is important and what has to be avoided can thus in particular be related to a certain process of education. As an example, actors concerned with curriculum development can directly learn from recommendations and experiences specifically for this process and do not have to deal with overall recommendations for implementing a guideline for instructional design in general. To restrict descriptions of experiences and recommendations to a certain model of process categories that is capable of covering the whole educational scenario therefore allows searching and comparing, but also assessing the impact which a certain quality approach has on certain educational processes.

2. Being aware of the difference between intentional and external effects: An educational organization, a course with its actors, teachers, learners, technical and administration staff can be conceptualized as an organic working system. Implementing a quality approach in this system or in specific parts of this system (e.g., guidelines for course authors, screen designers, or tutors) usually changes the whole system. There is no such thing like partial improvement of e-learning scenarios without affecting other interconnected processes and actors without producing so-called "external effects" or "side effects". In previous works, we described the interdependencies between technological processes, economical conditions, 
and educational services in e-learning environments [Ehle $\left.{ }^{+} 03 \mathrm{a}\right]$. A formal model for describing experiences can only cover incidents related to intentional improvement processes. Unintentional side effects are too context specific and rooted in singular specialties of individual constellations to be of specific value for other organizational contexts. Therefore, we are aware of the boundaries: To construct a model that is able to cover experiences for all educational contexts and processes in principal needs to be of a more generic nature. Of course, such a model has to allow for the possibility to describe external effects as well, but it can not specifically concentrate on these effects. To acknowledge this weakness of a formal model for describing individual experiences does not reduce the importance of such a model. It still leaves enough space to be of a helpful nature to other users of quality approaches.

3. Accepting the paradigm of co-production in the pedagogical scenario: $\mathrm{Al}-$ though of its prefix ' $e$ ', e-learning still remains learning. Learning processes are not led through producer driven structures only but rather constitute a process of co-production between the learner/the client and the educational environment. Quality approaches generally aim at improving processes on the side of the educational environment to - that's the philosophy - enhance the possibilities for the learner to improve in his/her own learning processes. The concept of empowerment describes this development and will eventually lead to a better understanding of what quality in e-learning for the learner could be. To accept the impossibility to direct the whole learning process and to steer it from the producer side, means also to give the floor to uncertainty. The learner has to be enabled, but will he also use the provided structures for a 'better' learning process? And, what if not? In exactly this field, experiences gain their importance for quality development because they provide knowledge that goes beyond the officially documented concepts. Actors in an educational scenario can often learn a lot more from these experiences than from their official quality-handbook or their guidelines because they get to know that the pure implementation of a quality approach alone is no guaranty for improvement processes. There still have efforts to be undertaken to learn how the learners react to the newly structured learning environments. These are very valuable experiences that are important to all educational professionals.

4. Accepting the difficulty of generalizing the singularity of events: To collect experiences, to structure them accordingly and thus make them comparable and applicable does not automatically mean that they are transferable. Experiences are highly dependent on a specific context in which they are made. They also are highly dependent on the view of the actor who contributes the experience, on the language he uses, and on the cognitive/affective structure and background of those who are perceiving the contribution. We are aware of this 'transfer problem'. Learning from experiences therefore does not mean that the plain transfer of experiences works. However, it is indisputable that the perception of reference knowledge - may it contradict or enforce ones own experience - can lead to a greater reflection of a situation and thus a greater competency. It is important to 
acknowledge that the pure provision of experiences can only stimulate learning processes on the users' side but that experiences can not be transferred directly to a different context. For our model we therefore suggest to ask users for their recommendations rather for an account of their experiences. It will become clear that the scope of recommendations is much more directed at providing usable knowledge to other users than the scope of experiences. Therefore it seems reasonable to aim at building a concept that provides recommendation for usage and implementation where users can learn from other users' experiences.

Against the background of these four conditions we suggest the following model to describe experience based recommendations for quality approach implementation processes.

\subsection{A Formal Model for Experience-Based Recommendations}

The European Quality Observatory has proposed a conceptual model which contains a section for the categorization of experiences and which serves as the basis for the following scheme [EQO03]. The proposed model therefore is strongly based on the EQO model for describing quality approaches and experiences. However, some of the categories proposed here are new to the original model and some categories of the original model are changed into similar or slightly different ones. Basically, we suggest to analyze experiences according to three different sections:

1. The first section collects general information about the context, where the experience took place and about the actors, who are reporting the experience. We believe that these background factors are constitutional for the assessment and for recommendations someone states. It will be interesting to analyze how actors from different contexts report about their experience with a quality approach in different ways. Research in this field can follow the question, how a certain context influences the impact that a quality approach has.

2. In the second section we want to collect the recommendations which actors have on basis of their experiences. In our model we propose a three step approach for this analysis. In a first step the user can choose a process from the process model for which he wants to state a recommendation (we use the process model of the CEN/ISSS WS LT, [CENI2002]). This concept follows the assumption that quality approaches are usually not affecting all processes in an educational scenario but are directed at a few specific ones. Therefore we want to give the user a specific option to choose a process which was affected by the quality approach and for which he/she then would like to contribute recommendations. In a second step we provide the possibility to specify what has been done resp. how the quality approach was instantiated for this specific process. With this description we lay the foundation for the next step in which we ask the user for a recommendation which is rooted in the experiences he/she has made. As stated above, we believe 
that asking the user not for an experience but for a recommendation leads to a more goal oriented, more specific information.

3. In a third section we then ask the user for an assessment of the overall quality approach. There are basically two methodological approaches to assess quality approaches: an open and qualitative way and a standardized, more quantitative way. The advantages of collecting assessments in a standardized and quantitative way are obvious because then they can be rated and ranked against users requirements. The question which quality approach is best against the background of a certain standardized item can be easily answered. But there are also problems with a standardized way of assessment because it follows the assumption that all quality approaches can be assessed on basis of the same criteria. This seems odd - not only because of the variety of contexts we already described above but also because of the even greater diversity of implementation contexts and actors. We therefore suggest a methodological mixture of approaches. In a first step, the user is asked to rate his assessment against a set of criteria we provide (e.g., "economical improvement": $60 \%$ success). In a second step he/she then can contribute his/her own criteria and provide an assessment for these (e.g., "comprehensiveness of the used expressions in the quality approach": $20 \%$ success). It is very important that users are able to refine the standardized categories by specifying their own because it can well be that an analysis category for "economical success" is plainly too broad for description.

In the retrieval interface, the individually specified assessment categories should be provided to users who are searching through the experiences. They also should be collected in a special index and connected to the search and browse options. Those keyword-lists will be a growing pool of evaluation criteria from the users perspective, on which basis the standardized items should regular be refined.

Table 2 shows the proposed formal model for describing experience based recommendations for quality approach implementation processes.

A. General Information and Context: Overall information of the quality approach application process

\begin{tabular}{|l|l|}
\hline Identifier & The quality approach description in the EQO database to
\end{tabular} which the described experience relates

1. Description of the organizational context of the experience.

\begin{tabular}{|l|l|}
\hline 1.1 Name & The name of the organization where the experience was
\end{tabular} made

\begin{tabular}{l|l} 
1.2 Country & The Country of the organization in which the experience
\end{tabular} with the QA was made 
1.3 Size of the organization where the experience took place

\begin{tabular}{|l|l|}
\hline 1.3.1 Size & Number of Employees \\
\hline 1.3.2 Project size & $\begin{array}{l}\text { Number of People involved in the quality approach imple- } \\
\text { mentation process }\end{array}$ \\
\hline $\begin{array}{l}\text { 1.4 Educational } \\
\text { Level }\end{array}$ & $\begin{array}{l}\text { Educational level of entity in which the quality approach } \\
\text { was implemented (e.g., school) }\end{array}$ \\
\hline
\end{tabular}

2. Contributor: Who contributed the experience/recommendation?

\begin{tabular}{|l|l|}
\hline 2.1 Status & $\begin{array}{l}\text { First contribution } \\
\text { Refined contribution }\end{array}$ \\
\hline 2.2 Function & Function of contributor within organization \\
\hline 2.3 Entity & Name, Address, etc. \\
\hline 2.4 Date & Date of contribution of experience \\
\hline $\begin{array}{l}\text { 2.5 Function of re- } \\
\text { sponsible actor }\end{array}$ & $\begin{array}{l}\text { Function of responsible actor for the current implementation } \\
\text { process within organization? }\end{array}$ \\
\hline
\end{tabular}

3. Prior experience with quality approach implementations

\begin{tabular}{|l|l|}
\hline 3.1 Description & $\begin{array}{l}\text { Specifies experiences with usage of quality approaches in } \\
\text { the past }\end{array}$ \\
\hline 3.2 Date & Date (year) of the prior experience \\
\hline 4. Time span & Duration of the current implementation process \\
\hline 4.1 Start Date & Approx. start date of implementation process \\
\hline 4.2 End Date & Approx. end date of implementation process \\
\hline 5. Description & Short account of implementation process \\
\hline 6. Target Group & $\begin{array}{l}\text { Who was/were the target group(s) of the quality approach } \\
\text { implementation? }\end{array}$ \\
\hline 7. Cost: Total implementation cost \\
\hline 7.1 Cost Model & $\begin{array}{l}\text { Direct (e.g., a certain amount for a certification process or } \\
\text { an external audit) or indirect costs (e.g., internal staff train- } \\
\text { ings, etc.) }\end{array}$ \\
\hline 7.1.1 Amount & Amount of money \\
\hline 7.1.2 Currency & $€$, US-\$, etc. \\
\hline 7.1.3 Description & Description of costs, especially indirect costs \\
\hline
\end{tabular}




\section{B. Recommendation}

1. Process: This category describes to which (educational) processes the quality approach was applied and specifies recommendations

\begin{tabular}{|l|l|}
\hline 1.1 Name & Name of the educational Process (CEN Model) \\
\hline 1.2 Relation & $\begin{array}{l}\text { Name of the educational process(es) from the originating } \\
\text { model (other process models) }\end{array}$ \\
\hline $\begin{array}{l}\text { 1.4 Recommenda- } \\
\text { tion }\end{array}$ & $\begin{array}{l}\text { Description of how the user instantiated this process with } \\
\text { regard to the quality approach (What was done?) }\end{array}$ \\
\hline
\end{tabular}

C. Assessment: Assessment of the experience and the actual effect of the quality approach

1. Quality concepts The user specifies how quality is defined in his/her view (Quality is... faultlessness, conformance to standards, excellence in performance and perfection, the best value for money, defined through pedagogical transformation and learning achievements)

\section{Assessment: The user assesses the quality approach}

\begin{tabular}{|l|l|}
\hline $\begin{array}{l}\text { 2.1 Name of stan- } \\
\text { dard criteria }\end{array}$ & $\begin{array}{l}\text { User chooses from Standard-Criteria for assessment (Qual- } \\
\text { ity of... institutional and executive commitment, techno- } \\
\text { logical infrastructure, student services, instructional design } \\
\text { and course development, instruction and instructors, pro- } \\
\text { gram delivery, financial health, regulatory and legal com- } \\
\text { pliance, evaluation and assessment procedures) }\end{array}$ \\
\hline $\begin{array}{l}\text { 2.1.1 Assessment } \\
\text { Value }\end{array}$ & $\begin{array}{l}\text { This element describes the contributors expert assessment } \\
\text { regarding the enhancement of the quality of the specific cri- } \\
\text { teria. }\end{array}$ \\
\hline $\begin{array}{l}\text { 2.1.2 Importance } \\
\text { Weight }\end{array}$ & $\begin{array}{l}\text { This element describes the importance that the specific cri- } \\
\text { teria had for the application of the specific quality approach. }\end{array}$ \\
\hline $\begin{array}{l}\text { 2.2 Name of user } \\
\text { specific criteria }\end{array}$ & Description of users' own assessment criteria \\
\hline
\end{tabular}




\begin{tabular}{|l|l|}
\hline $\begin{array}{l}\text { 2.2.1 Assessment } \\
\text { Value }\end{array}$ & $\begin{array}{l}\text { This element describes the contributors expert assessment } \\
\text { regarding the enhancement of the quality of the specific } \\
\text { criteria }\end{array}$ \\
\hline $\begin{array}{l}\text { 2.2.2 Importance } \\
\text { Weight }\end{array}$ & $\begin{array}{l}\text { This element describes the importance that the specific cri- } \\
\text { teria had for the application of the specific quality ap- } \\
\text { proach }\end{array}$ \\
\hline 3. Success Factors & $\begin{array}{l}\text { Free text description of what have been proved to be key } \\
\text { factors of success }\end{array}$ \\
\hline 4. Failure Factors & $\begin{array}{l}\text { Free text description of what have been proved to be key } \\
\text { factors of failure }\end{array}$ \\
\hline
\end{tabular}

Table 2: Formal model for experiences

\section{Conclusion}

We have shown that quality development as a knowledge intensive (business) process can be supported by different knowledge management strategies, such as codification and/or personalization. The described approach shows how experiences from one specific context (e.g., quality approach implementation in a high school) can be reused for other contexts in form of recommendations. We showed that knowledge management concepts can be used in the area of quality development. This integration of concepts becomes fruitful because quality development in organizational contexts implies individual actors' learning processes which can be improved by sharing experiences. The suggested formal model represents a codification strategy by specifying information categories for substantially important fields concerning the topic of implementation, context, and assessment for quality approach implementation processes.

The implementation of the model in form of a database will lead to a growing pool of structured data that allows users to reuse other users' knowledge for their own purposes and contexts. In the field of experiences and reusing of knowledge, it is important to acknowledge certain conditions, stated above, that constitute the boundaries of such an approach. Nevertheless, it is important to proceed with the development of knowledge tools that allow to provide structured access to recommendations and thus help in decision situations [EhPa2003]. Experiences in a database which are structured according to the above suggested formal model could be directly mapped to certain context variables, and therefore provide valuable knowledge for specific requirements, e.g., if a user is searching for specific recommendations for the university level. The research in the field of experiences 
in the implementation of quality approaches for educational contexts will deliver important knowledge on impact and effects that will lead to an overall improvement of quality development in education.

However, we made clear that quality development also needs a personalization strategy for sharing experiences. This strategy must be supported by the codification strategy in order to enable people to build their success on experiences. This can be integrated into the quality development in form of communities for exchange and reflection but also in form of more organized organizational forms of information and knowledge exchange.

\section{References}

[ABLP2004] Adelsberger, H.H.; Bick, M., Lodzinski; T., Pawlowski, J.M.: Electronic Performance Support Systems in Production and Operations Management - State of the Art and Future Development. Submitted: FACES 3 (2004) 5.

[Albr1993] Albrecht, F.: Strategisches Management der Unternehmensressource Wissen [Strategic Management of Knowledge]. Peter Lang, Frankfurt 1993.

[CENI2002] CEN/ISSS Workshop Learning Technologies: CWA14644 Quality Assurance Standards, CEN, Brussels 2002.

[Druc1994] Drucker, P. F: Post-Capitalist Society. Harper Business, New York 1994.

[EGHJ2003a] Ehlers, U.-D.; Gerteis, W., Holmer; T., Jung, H. (ed.): E-learning-Services im Spannungsfeld von Pädagogik, Ökonomie und Technologie. L $^{3}$-Lebenslanges Lernen im Bildungsnetzwerk der Zukunft. W. Bertelsmann, Bielefeld 2003.

[Ehle2004] Ehlers, U.-D.: Qualität im E-Learning aus Lernersicht. Grundlagen, Empirie und Modellkonzeption subjektiver Qualität. Verlag für Sozialwissenschaften, Wiesbaden 2004

[EhPa2003] Ehlers, U.-D.; Pawlowski, J.M.: Qualitätsentwicklung im E-Learning: Ein Entscheidungsmodell für die Auswahl von Qualitätsansätzen in Europa, In: Fietz, G., Godio, C., Mason, R.: eLearning für internationale Märkte. Entwicklung und Einsatz von eLearning in Europa. W. Bertelsmann, Bielefeld 2003.

[EhPG2003] Ehlers, U.-D.; Pawlowski, J.M.; Goetz, L.: Qualität von E-learning kontrollieren, Die Bedeutung von Qualität im E-learning, In: Hohenstein, A., Wilbers, K.: Handbuch E-learning, Expertenwissen aus Wissenschaft und Praxis: Strategien, Instrumente, Verlag Deutscher Wirtschaftsdienst, Köln 2003.

[EHPT2004] Ehlers, U.-D.; Hildebrandt, B.; Pawlowski, J.M.; Teschler, S.: The European Quality Observatory. Enhancing Quality for Tomorrow's Learners. Conference Proceedings of 3. EDEN Research Workshop 03/2004, Oldenburg 2003. 
[EQO2004] European Quality Observatory: European Quality Observatory: The EQO Model, Draft Paper version 1.2, University of Duisburg-Essen, http://www.eqo.info, 2004, Extracted on 01-07-2004.

[HaNT1999] Hansen, M. T.; Nohria, N.; Tierney, T.: What's Your Strategy for Managing Knowledge? In: Harvard Business Review, 77, (1999), 3-4, pp. 106-116.

[Klos2001] Klosa, O.: Wissensmanagementsysteme in Unternehmen: State-of-the-Art des Einsatzes [Knowledge Management Systems in Organizations: State-of-the-Art]. Deutscher Universitäts-Verlag, Wiesbaden 2001.

[Lehn2000] Lehner, F.: Organisational Memory. Hanser, Munich 2000.

[MaHä2001] Maier, R.; Hädrich, T.: Modell für die Erfolgsmessung von Wissensmanagementsystemen [A model to measure success of knowledge management systems]. In: WIRTSCHAFTSINFORMATIK 43 (2001) 5, pp. 497-509.

[Maie2001] Maier, R.: State-of-Practice of Knowledge Management Systems: Results of an Empirical Study. In: INFORMATIK/INFORMATIQUE (2001) 1, pp. 14-22.

[Maie2002] Maier, R.: Knowledge Management Systems: Information and Communication Technologies for Knowledge Management. Springer, Berlin 2002.

[MaSA2004] Manouselis, N.; Sampson, D.: A Multi-criteria Model to Support Automatic Recommendation of e-Learning Quality Approaches, Proceedings of the 16th World Conference on Educational Multimedia, Hypermedia and Telecommunications (EDMEDIA 2004), Lugano, Switzerland, June 2004.

[Remu2002] Remus, U.: Prozessorientiertes Wissensmanagement [Process-oriented Knowledge Management]. PhD-Thesis. University of Regensburg 2002.

[ReRa2001] Reeves, T.C.; Raven, A.: Performance-Support Systems. In: Adelsberger, H.H., Collis, B., Pawlowski, J.M. (Eds.): Handbook on Information Technologies for Education \& Training. International Handbook on Information Systems Series, Springer, Berlin 2001. 
